\title{
Meningkatkan Kemampuan Baca Kitab Santri PP Sabilul Huda dengan Bimbingan Baca Kitab Menggunakan Kitab Al-Miftah Lil'ulum
}

\section{Muhammad Farid Nasrulloh, Muhammad Syafiuddin Shobirin, Rina Dian Rahmawati, Syaifuddin}

\author{
Pendidikan Agama Islam \\ Universitas KH. A. Wahab Hasbullah Jombang, Jl. Garuda No. 09 Jawa Timur \\ Email: faridnasrulloh@unwaha.ac.id
}

\begin{abstract}
Abstrak
Tujuan dari pengabdian ini antara lain untuk mengetahui penerapan metode Baca Kitab Al-Miftah dipondok pesantren sabilul huda dan untuk mengetahui pentingnya kitab Al-Miftah lilulum dipondok pesantren Sabilul Huda. Pengabdian ini dilaksanakan di Pondok Pesantren Sabilul Huda Jombang. Program Pengabdian ini diikuti oleh santri yang mengikuti kelas Madrasah Diniyah. Metode pelaksanaan pengabdian kegiatan di Pesantren ini meliputi metode ceramah dan praktek. Hasil dari pelaksanaan pengabdian masyarakat ini sebagai berikut: (1) Pada umumnya semua program dapat terlaksana dengan baik, antusias santri dalam mengikuti kegiatanbimbingan baca Kitab Al-Miftah sangat baik sekali, sehingga program kerja yang kami laksanakan sudah sesuai dengan kondisi yang ada. (2) Suksesnya program pengabdian ini karena didukung dan ditunjang oleh kerja tim yang baik, baik dari tim maupun para santri di Pondok Sabilul Huda. (3) Dalam bidang pendidikan khususnya bimbingan baca kitab AlMiftah banyak santri-santri yang sangat antusias, ini menjadi acuan bahwasanya pengabdian menjadi jembatan motivasi santri. (4) Dengan adanya pengabdian di pesantren, dapat mempererat tali silaturrahmi dan meningkatkan ketakwaan kepada Allah SWT. (5) Program-program yang telah dilaksanakan sangat membantu santri dalam mempelajari ilmu Nahwu dan Shorof yang dikemas dalam Kitab Al-Miftah, serta banyak hal positif yang dapat diambil sebagai bekal dan pengalaman yang berharga.
\end{abstract}

Kata Kunci: Kemampuan Baca Kitab, Baca Kitab, Al Miftah Lil'ulum

\section{Pendahuluan}

Pondok pesantren merupakan basis lembaga pendidikan islam paling kuno di indonesia, Pesantren merupakan lembaga pendidikan yang unik. Tidak saja karena keberadaannya

yang sudah sangat lama, tetapi juga karena kultur, metode, dan jaringan yang diterapkan oleh lembaga agama tersebut (Syafe'i, 2017). Pesantren menekankan isi/materi pembelajarannya pada hasil karya ulama-ulma salaf terdahulu yang pada akhirnya dikenal dengan istilah kutup al- shafra' (kitab kuning), kitab kuning yang dipelajari dan diajarkan kepada santri dipondok pesantren, umumnya berhaluan ahli sunnah waljamaah, baik segi akidah, fikih, maupun tasawufnya. Kitab kuning sering disebut dengan kitab gundul, karena tidak memiliki harakat atau syakl, seperti fatkhah, kasrah, dhammah dan sukun (Restu \& Wahyuni, 2019). Diantara peran penting dalam mempelajari dan menguasai isi dari kitab kuning secara komprehensif adalah penguasaan ilmu alat. IImu alat yang dimaksut adalah nahwu dan shorof. IImu tersebut menjadi studi paling diprioritaskan dipesantren sebagai upaya untuk menjadikan santri sebagai kader-kader yang memiliki paham benar dan baik terhadap AI-Qur'an dan sunnah melalui penjelasan ulama dalam kitab kuningnya.

Metode pembelajaran bahasa arab telah mendapatkan perhatian dari para ahli pembelajaran bahasa dengan melakukan berbagai kajian dan penelitian dalam rangka untuk mengetahui efektivitas dan kesuksesan berbagai metode pembelajaran (Sam, 2016). Penggunaan dan pemilihan metode merupakan hal yang mempengaruhi proses dan hasil pembelajaran bahasa arab (Aminah, 
2020). Metode Al-Miftah Lil Ulum sendiri merupakan rangkuman padat dari kitab jurumiah, imrithi dan alfiyah. Oleh sebab itu, dalam metode ini tidak dimunculkan istilah-istilah baru dalam ilmu nahwu, bahkan tetap mempertahankan keorginalitasan istilah dari kitab. Pesantren sendiri merupakan wadah bagi para santri untuk meningkat belajar dan sejauh mana ilmu didapatkan ketika sudah terjun dimasyarakat. Dalam kenyataannya selama ini merupakan program kegiatan yang diterapkan pada lembaga pendidikan perguruan tinggi. Subyek dalam pengabdian ini adalah pengurus, dan santri beserta tim yang berada dipondok sabilul huda. Adapun pengumpulan datanya menggunakan metode kitab Al-Miftah, wanwancara, observasi dan dokumentasi.

Pengabdian ini menggunakan metode kitab Al-Miftah lil'ulum yang sejalan dengan penelitian yang telah dilakukan oleh Maulana Restu dan Siti Wahyuni (2019) dengan judul "Implementasi Metode Al Miftah Lil Ulum Dalam Membaca Kitab Fathul Qorib Bagi Pemula Di Pondok Pesantren Sidogiri Salafi Kabupaten Pasuruan". Penelitian ini menyimpulkan bahwa implementasi kitab Al Miftah Lil Ulum dapat menjadi daya pikat semangat santri, belajar kitab kuning menjadi semakin mudah, menumbuhkan semangat dan gairah belajar membaca kitab kuning, prestasi membaca kitab semakin meningkat dan memberikan rasa percaya diri semakin meningkat. Penelitian dengan menggunakan metode kitab Al-Miftah lil'ulum juga telah dilakukan oleh Sari (2018), penelitian ini menyimpulkan bahwa Metode Al-Miftah Lil Ulum adalah metode baca kitab yang sesuai untuk dipelajari bagi tingkat pemula.

\subsection{Tujuan Kegiatan}

Tujuan dari pengabdian ini antara lain untuk mengetahui penerapan metode Baca Kitab AlMiftah dipondok pesantren sabilul huda dan untuk mengetahui pentingnya kitab Al-Miftah lilulum dipondok pesantren Sabilul Huda. Target yang harus kita capai dalam lembaga pendidikan dipondok pesantren sabilul huda khususnya diwilayah pondok pesantren Bahrul ulum diharapkan memberikan pengaruh yang positif terhadap pengembangan kualitas pembelajaran, keterampilan terhadap pondok pesantren yang lainnya. Selain itu, diharapkan dapat memotivasi kepada pondok yang lain agar terus berkarya dan menjadi panutan serta dapat mendukung kegiatan yang berada dipondok pesantren Bahrul Ulum.

\subsection{Manfaat Kegiatan}

Manfaat yang diharapkan dari pelatihan ini adalah Santri memiliki pengetahuan mengenai baca kitab kuning. Guru dapat memiliki pengetahuan metode kitab Al-Miftah dengan Metode yang lainnya. Para guru dapat memiliki pengetahuan dalam memanfaatkan lingkungan kelas sebagai media belajar. Para santri dapat memiliki pengetahuan Metode kitab Al-Miftah dengan Metode yang lainnya.

\subsection{Luaran Pengabdian Kepada Masyarakat}

Target Luaran dalam kegiatan pengabdian kepada masyarakat ini, yaitu:

a. Mampu mempelajari kitab kuning dengan mandiri

b. Tumbuhnya semangat Santri-santri untuk membaca kitab kuning

c. Mampu memahami membaca kitab kuning

\section{Realisasi Kegiatan}

\subsection{Bentuk Kegiatan \& Jadwal, Serta Tempat Kegiatan \\ a. Metode Pelaksanaan Kegiatan}

Metode pelaksanaan untuk pelaksanaan pengabdian kegiatan diPesantren ini meliputi metode ceramah dan praktek. Metode ceramah dan praktek dilaksanakan pada kegiatan sosialisasi pembelajaran berlangsung. Metode yang digunakan pada kegiatan ini adalah mengunakan metode kitab Al-Miftah lilulum. Melalui kegiatan pelatihan ini diharapkan dapat menyelesaikan permasalahan yang dihadapi oleh pihak mitra. Selain menghapalkan materi yang ada, santri juga diminta untuk menulis (write), karena dengan menulis dengan bahasanya sendiri, maka santri akan lebih cepat untuk memahami materi yang disampaikan (Nasrulloh \& Umardiyah, 2020). Berikut Tabel 2 menampilkan solusi sebagai penyelesaian rumusan permasalahan yang ada. 
Tabel 1. Sosuli Permasalahan

\begin{tabular}{|l|l|l|}
\hline No & Permasalahan & Solusi \\
\hline 1. & $\begin{array}{l}\text { Kurang optimalnya pembelajaran didalam kelas untuk } \\
\text { meningkatkan kemampuan metakognitif peserta didik }\end{array}$ & $\begin{array}{l}\text { 1. Teori } \\
\text { 2. Praktek }\end{array}$ \\
\hline 2. & Kurangnya mutalaah & $\begin{array}{l}\text { 1. Belajar } \\
\text { 2. Lalaran }\end{array}$ \\
\hline
\end{tabular}

Metode ceramah dan praktek yang digunakan dilaksanakan selama pertemuan dengan struktur pelaksanaan kegiatan ini sebagai berikut.

Tabel 2. Struktur Pelatihan Kitab Al-Miftah lilulum

\begin{tabular}{|c|c|c|c|c|}
\hline No & Materi & Kegiatan & Jumlah jam & Jumlah peserta \\
\hline \multicolumn{5}{|c|}{ Pertemuan 1} \\
\hline 1 & $\begin{array}{l}\text { Pengenalan kitab } \\
\text { Al-Miftah }\end{array}$ & 1. Sosialisasi & 1 & 18 \\
\hline 2 & Kalam & 1. Presentasi & 1 & 18 \\
\hline 3 & Asmaul Khomsah & $\begin{array}{l}\text { 1. Presentasi } \\
\text { 2. Teori } \\
\text { 2. Praktek }\end{array}$ & 3 & 18 \\
\hline \multicolumn{5}{|c|}{ Pertemuan 2} \\
\hline 1 & Isim Nakiroh & 1. Presentasi & 1 & 18 \\
\hline 2 & $\begin{array}{ll}\text { Mudzakkar dan } \\
\text { Muannas }\end{array}$ & $\begin{array}{l}\text { 1. Teori } \\
\text { 2. Praktek }\end{array}$ & 3 & 18 \\
\hline 3 & Isim jamid & 1. Presentasi & 1 & 18 \\
\hline \multicolumn{5}{|c|}{ Pertemuan 3} \\
\hline 1 & Kalimat Fi'il & $\begin{array}{l}\text { 1. Presentasi } \\
\text { 2. Teori } \\
\text { 3. Praktek }\end{array}$ & 3 & 18 \\
\hline 2 & Mujarrod dan Mazid & $\begin{array}{l}\text { 1. Presentasi } \\
\text { 2. Teori }\end{array}$ & 2 & 18 \\
\hline 3 & $\begin{array}{l}\text { Fi'il muta'adi dan } \\
\text { Lazim }\end{array}$ & $\begin{array}{l}\text { 1. Presentasi } \\
\text { 2. Teori }\end{array}$ & 3 & 18 \\
\hline \multicolumn{5}{|c|}{ Pertemuan 4} \\
\hline 1 & Isimnya Kana & $\begin{array}{l}\text { 1. Presentasi } \\
\text { 2. Praktek }\end{array}$ & 2 & 18 \\
\hline 2 & $\begin{array}{l}\text { Mubtadak dan } \\
\text { Khobar }\end{array}$ & $\begin{array}{l}\text { 1. Presentasi } \\
\text { 2. Praktek }\end{array}$ & 2 & 18 \\
\hline 3 & Isimnya Inna & $\begin{array}{l}\text { 1. Presentasi } \\
\text { 2. Praktek }\end{array}$ & 2 & 18 \\
\hline
\end{tabular}

\section{b. Waktu Efektif Pelaksanaan Kegiatan}

Kegiatan Pelaksanaan Pengabdian Kepada Masyarakat ini akan dilaksanakan pada Tanggal 21 September s.d 16 Nopember 2020 dengan rincian sebagai berikut:

Tabel 3. Jadwal Pelaksanaan

\begin{tabular}{|c|l|c|c|c|c|c|c|}
\hline \multirow{2}{*}{ NO } & \multicolumn{5}{|c|}{ Kegiatan } & \multicolumn{5}{c|}{ Jadwal Pelaksanaan Tanggal : } \\
\cline { 4 - 7 } & & $\mathbf{2 1}$ & $\mathbf{5}$ & $\mathbf{1 2}$ & $\mathbf{1 9}$ & $\mathbf{2 6}$ & $\mathbf{1 6}$ \\
\hline $\mathbf{1}$ & Pembuatan Proposal & & & & & & \\
\hline 2 & Pelaksanaan Pengabdian Pertemuan 1 & & & & & & \\
\hline 3 & Pelaksanaan Pengabdian Pertemuan 2 & & & & & & \\
\hline 4 & Pelaksanaan Pengabdian Pertemuan 3 & & & & & & \\
\hline 5 & Pelaksanaan Pengabdian Pertemuan 4 & & & & & & \\
\hline 6 & Penyusunan Laporan & & & & & & \\
\hline
\end{tabular}

\section{c. Tempt Kegiatan}

Tempat pelaksanaan pengabdian kepada masyarakat ini beralamat: Tambak Rejo, Kec. Jombang, Kabupaten Jombang, Jawa Timur 61413 


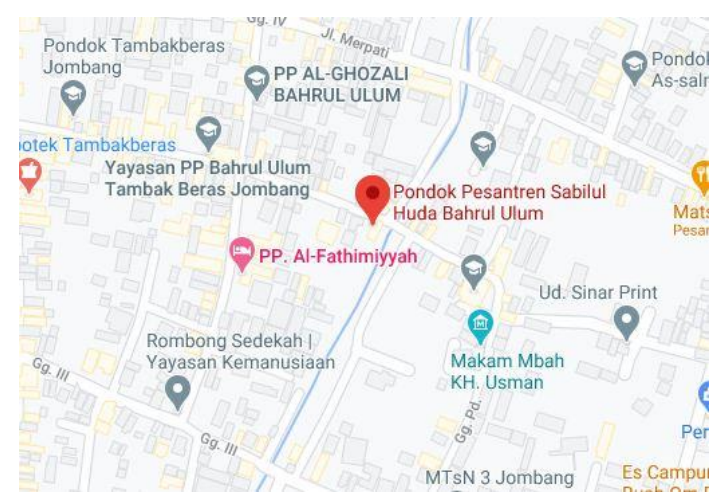

Gambar 1. Maps Lokasi

\subsection{Materi}

Metode Al-Miftah lil ulum merupakan metode yang berdasarkan pada landasan konteks yang menyenangkan dan situasi yang penuh kegembiraan dimana materi-materi pembelajaran tersebut dirinci sedemikian mudah dengan berbagai metode, media dan lagu-lagu.Metode ini menggunakan 4 jilid buku sebagai pedomannya, tetapi tetap mengacu pada matan Al-jurumiah, sehingga tidak memunculkan istilah dan bahasa baru. Dengan demikian santri bisa mempelajari dengan mudah, serta dikemas dalam bentuk lagu. Adapun rincian isi kitab 4 jilid tersebut sebagai berikut :

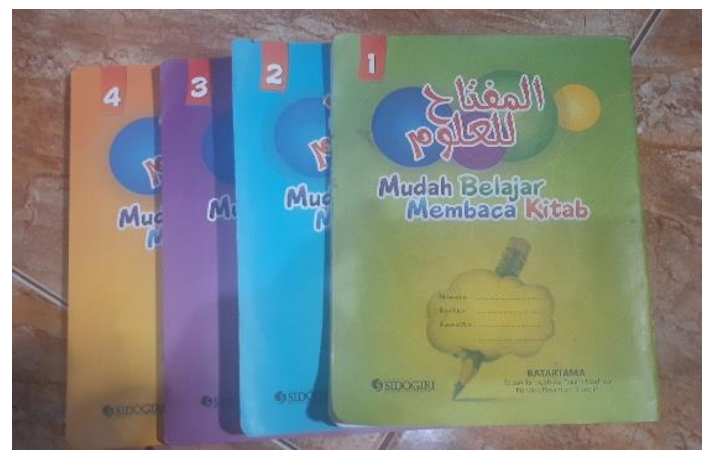

Gambar 2. Kitab Al-Miftah Lil'ulum Jilid 1-4

Jilid I membahas tentang bab kalimat (isim, fi'il dan huruf) dan isim ghoiru munshorif (illat 1 dan illat 2 (sifat dan alami).

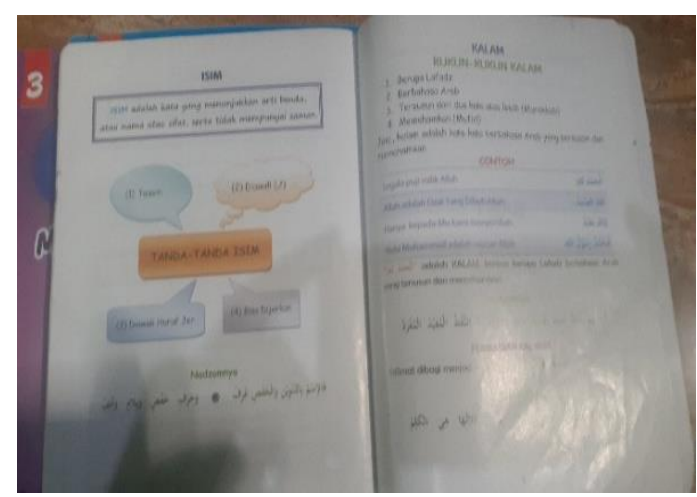

Gambar 3. Kitab Al-Miftah Lil'ulum Jilid 1

Jilid II membahas tentang isim (nakirah dan isim ma'rifat, isim mudzakar dan isim muannats, isim jamid dan isim mustaq). 


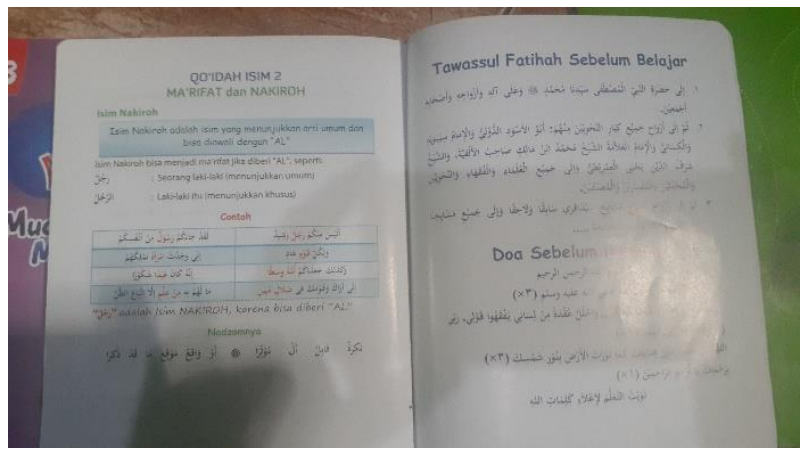

Gambar 4. Kitab Al-Miftah Lil'ulum Jilid 2

Jilid III membahas tentang fi'il (madhi, mudlori', dan amar, mujarrod, dan mabni, lazim dan mutaaddi, ma'lum dan majhul, shohih dan mu'tal).

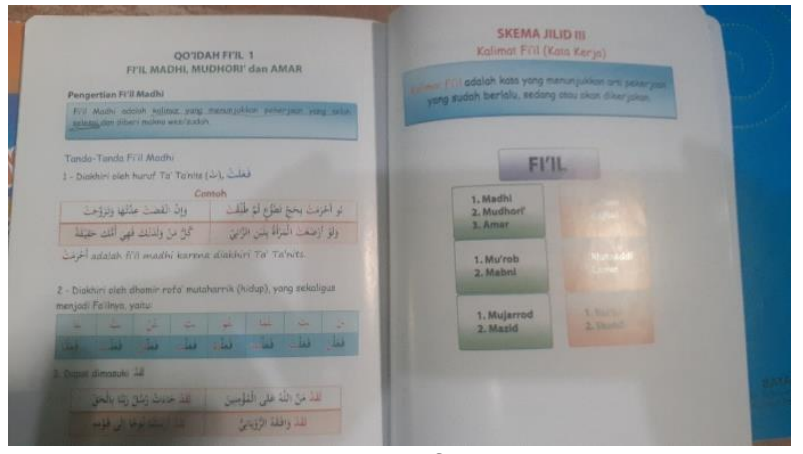

Gambar 5. Kitab Al-Miftah Lil'ulum Jilid 3

Jilid IV membahas tentang marfuatul asma' (fa'il, naibul fa'il, mubtada', khobar, isimnya kana, khobarnya inna dan tawabi') mansubatul asma' (maf'ul, khal, tamyiz, isimnya inna, khobarnya kana, maf'ulnya dhonna, isimnya la, mustana bi illa, munaddi dan tawabi') dan makhfudotul asma' (majrur bi harfi, mudhof ilaih dan tawabi').

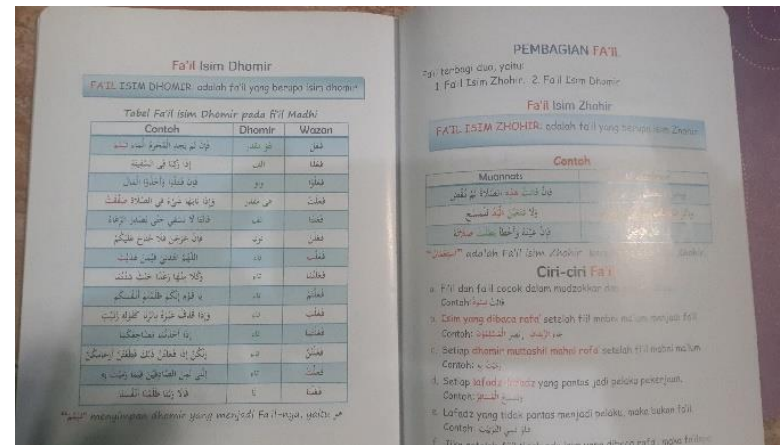

Gambar 6. Kitab Al-Miftah Lil'ulum Jilid 4

\subsection{Masyarakat Sasaran}

Sararan dari pengabdian ini adalah masyarakat santri, khususnya santri-santri yang ada di Pondok Pesantren Sabilul Huda Tambakberas Jombang. 


\section{Tinjauan Hasil Yang Dicapai}

Pelaksanaan kegiatan pengabdian di Pesantren ini didukung oleh beberapa pihak salah satunya adalah Lembaga Penelitian dan Pengabdian Masyarakat (LPPM) UNWAHA yang bekerja sama dan bersinergi dalam hal sumber daya manusia dengan pihak Fakultas dan Program Studi sesuai dengan kegiatan yang akan dilaksanakan. Kegiatan ini akan mencapai keberhasilan dan kelancaran karena adanya kerjasama dengan pihak mitra (sasaran) dimana sumber permasalahan diperoleh dari pihak mitra tersebut.

Pelaksanaan ini bersifat partisipatori, dimana tim yang melaksanakan pengabdian dan mitra secara bersama-sama dan proaktif untuk terlibat dalam setiap kegiatan. Pelaksanaan kegiatan pengabdian di pesantren dilakukan di Bulan Oktober 2020. Kegiatan dilaksanakan dalam bentuk sosialisasi, pelatihan, dan pendampingan melalui empat kali pertemuan atau tatap muka. Pelaksanaan kegiatan ini dilakukan di lembaga Pondok Pesantren Sabilul Huda Tambakberas Jombang.

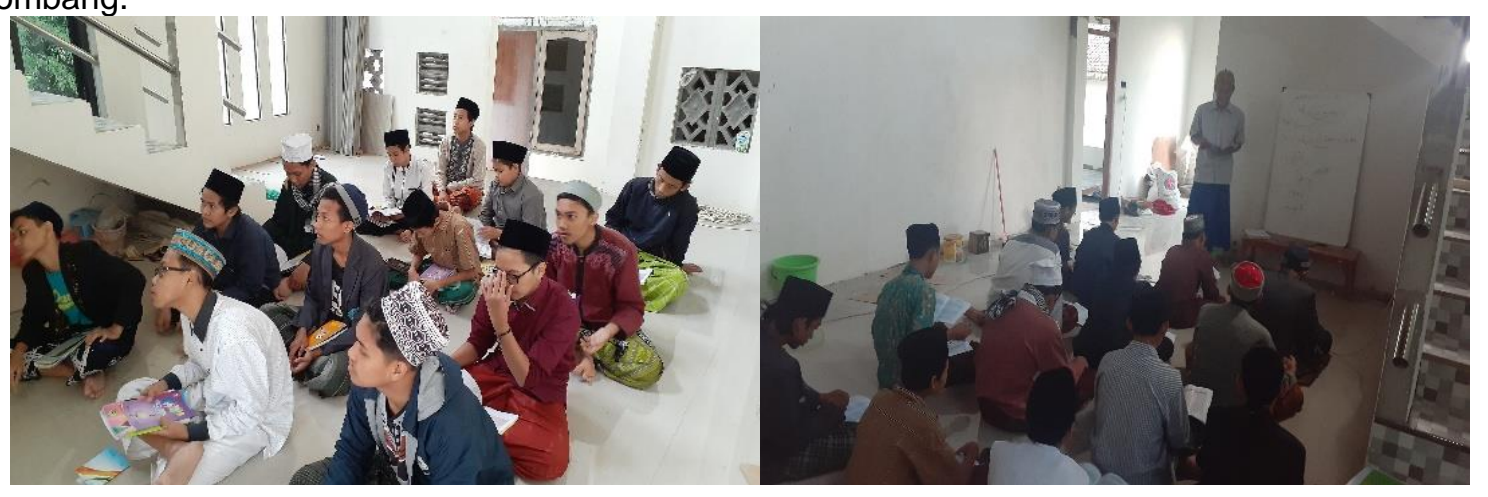

Gambar 7. Pelaksanaan Pengabdian

Kegiatan pelaksanaan mengenai Kitab Al-Miftah lil'Ulum guna untuk meningkatkan daya tarik baca Kitab kuning baik kualitas dan kuantitas agar supaya kedepannya bisa lebih baik, mandiri dan bisa mengamalkan ilmunya yang telah diberikan oleh tim yang melaksanakan pengabdian. Kegiatan ini santri bukan hanya menghafal dan membaca akan tetapi santri juga harus mencatat apa yang telah disampaikan oleh guru dengan itu santri bisa belajar mandiri karena sudah mempunyai catatan, hafalannya tetap bisa dijaga. Kemudian setelah semua terlaksana para santri juga bisa diuji sejauh mana ilmu yang didapat selama kegiatan belajar berlangsung yaitu : melalui tes tulis maupun tes lisan dengan itu guru bisa membedakan santri yang sudah faham dengan santri yang perlu ada bimbingan secara intensif. Berikut hasil nilai yang didapatkan oleh santri:

Tabel 4. Daftar Nilai nahwu dan Shorof

\begin{tabular}{|l|l|l|l|l|}
\hline No & Nama Santri & Ujian tulis & Ujian Lisan & Keterangan \\
\hline 1 & A. Qolfathirius & 90 & 80 & Lulus \\
\hline 2 & Abdul Ghofur & 88 & 85 & Lulus \\
\hline 3 & Atho' Najamuddin & 85 & 80 & Lulus \\
\hline 4 & M. Aqil Musthafa & 40 & 50 & Tidak lulus \\
\hline 5 & M. Fadhil Ramadhan & 80 & 90 & Lulus \\
\hline 6 & M. Nawaal Kamalannuja & 50 & 60 & Tidak lulus \\
\hline 7 & M. Umar Syafiq Albana & 80 & 85 & Lulus \\
\hline 8 & M. Zahir Nafi'udin & 80 & 80 & Lulus \\
\hline 9 & Sulthon Malikul Qahar & 90 & 90 & Lulus \\
\hline 10 & Zidni Huda A. & 85 & 85 & Lulus \\
\hline 11 & M. Iqbal & 80 & 80 & Lulus \\
\hline 12 & Nauwal Balya & 88 & 90 & Lulus \\
\hline
\end{tabular}




\begin{tabular}{|l|l|l|l|l|}
\hline 13 & Angga Syahputra & 85 & 80 & Lulus \\
\hline 14 & Yukhadal Hari & 90 & 80 & Lulus \\
\hline 15 & Ananda Aziz & 80 & 80 & Lulus \\
\hline 16 & Sanabilul Fahmi & 88 & 80 & Lulus \\
\hline 17 & Alfan Najami & 90 & 80 & Lulus \\
\hline 18 & M. Nizar & 60 & 50 & Tidak Lulus \\
\hline
\end{tabular}

Rencana jangka panjang dari kegiatan pengabdian di Pesantren ini melalui pengembangan dan peningkatan keterampilan membaca kitab para santri. Kegiatan ini dapat dilakukan terus-menerus dengan menyesuaian perkembangan zaman. Keberlanjutan program ini perlu dikomunikasikan dan dikoordinasikan dengan pihak yang berada di lembaga swadaya di wilayah kabupaten Jombang sehingga ke depannya dapat dilaksanakan secara lebih luas lagi. Tindak lanjut dari kegiatan ini akan dilakukan melalui kegiatan perluasan penerapan Metode Baca Kitab Al-Miftah lilulum. Kegiatan ini mengahasilkan Santri menjadi lebih terampil membaca kitab dan semangat untuk mempelajari kitab kuning.

\section{Daftar Pustaka}

Aminah, S. N. (2020). METODE-METODE PEMBELAJARAN BAHASA ARAB (No. 0). 4(0), 159-169.

Nasrulloh, M. F., \& Umardiyah, F. (2020). Efektivitas Strategi Pembelajaran Think-Talk-Write (TTW) Ditinjau dari Kemampuan Berpikir Kritis dan Komunikasi Matematis. Jurnal Mercumatika: Jurnal Penelitian Matematika Dan Pendidikan Matematika, 5(1), 69-76. https://doi.org/10.26486/jm.v5i1.1322

Restu, M., \& Wahyuni, S. (2019). Implementasi Metode Al Miftah Lil Ulum Dalam Membaca Kitab Fathul Qorib Bagi Pemula Di Pondok Pesantren Sidogiri Salafi Kabupaten Pasuruan. Jurnal Intelektual: Jurnal Pendidikan dan Studi Keislaman, 9(3), 263-272. https://doi.org/10.33367/ji.v9i3.1025

Sam, Z. (2016). METODE PEMBELAJARAN BAHASA ARAB. NUKHBATUL'ULUM: Jurnal Bidang Kajian Islam, 2(1), 23.

Sari, N. K. (2018). ANALISIS METODE AL-MIFTAH LIL ULUM SEBAGAI MEDIATOR METODE MEMBACA KITAB KLASIK DI PONDOK PESANTREN TERPADU AL-YASINI. Seminar Nasional Bahasa Arab Mahasiswa II Tahun 2018, 15.

Syafe'i, I. (2017). PONDOK PESANTREN: Lembaga Pendidikan Pembentukan Karakter. Al-Tadzkiyyah: Jurnal Pendidikan Islam, 8(1), 61. https://doi.org/10.24042/atjpi.v8i1.2097 